\title{
IUFOST2006/1344
}

\section{Agricultural Research in Africa to improve African Rural Economy, Agriculture, Nutrition and Food Security - Role and Initiatives of the Forum for Agricultural Research in Africa}

\author{
M. Jones ${ }^{\mathrm{a}}$ and J.-C. Legoupil ${ }^{\mathrm{b}}$ \\ ${ }^{a}$ FARA, PMB CT 173 Cantonments, GP1628 Accra, Ghana \\ ${ }^{\text {b}}$ FARA, PMB CT 173 Cantonments, 2 Gowa Close, Roman Bridge, GP1628 Accra, Ghana \\ jclegoupil@fara-africa.org
}

The people, culture and natural resources of the African continent are very diverse and complex, with enormous potential, but there are approximately 200 million people in Africa who are chronically hungry. African challenge to achieve food security will compel to improve resource productivity, to ensure sustainable livelihoods for the population with equitable access to social, economic and natural resources. In this respect, the African agricultural research and development organizations built a coalition that created the Forum for Agricultural Research in Africa (FARA). FARA's mission is "to enhance and add value to the effectiveness and efficiency of agricultural research systems in Africa in order to contribute to agricultural development and economic growth and sustainable use of natural resource".

The regional initiatives developed by FARA (Framework for African Productivity - FAAP; Sub-Saharan Africa Challenge Programme - SSA CP; Building African Scientific and Institutional Capacity - BASIC; Regional Agricultural Information and Learning Systems - RAILS and the African Biotechnology and Biosafety Initiative - ABBI) will contribute to strengthen the links between health, nutrition and food security in Africa. Food production should emphasize on increase not only in food quantity, but also in the quality of nutritional intake. This will be achieved through increased awareness of food nutritional value, enhancement of nutritional contents through research, training on basic health tips, and awareness of inputs specifics such as fertilizers or pesticides. The objective is to get agricultural interventions to include nutritional value and education. Policies and programs should not look only at food production for its economic gain but should also put emphasis on food security and people's health.

Key words: Research, Agricultural production, Food security 